КУРЮКИН Андрей Николаевич - кандидат политических наук, старший научный сотрудник Центра комплексных социальных исследований Института социологии Федерального научно-исследовательского социологического центра РАН (117218, Россия, г. Москва, ул. Кржижановского, 24/35, кopn. 5; kuriukin@mail.ru)

\title{
ЦИФРОВЫЕ ТЕХНОЛОГИИ В ВЫБОРНЫХ ПРОЦЕССАХ КАК ВЫЗОВ ПЕРСПЕКТИВАМ ДЕМОКРАТИИ
}

Аннотация. Цифровое общество - реальность современного этапа развития цивилизации. Сегодня его изучают в разных сферах и отраслях общественной жизни. Во всех из них констатируется создание новой реальности, вызванной интеграцией цифровых технологий в ту среду, которую те или иные сферы в себе объединяют. Данная статья анализирует практику интеграции указанных технологий в виде психометрического анализа больших данных. Автор предлагает прогноз перспективного развития политической системы в условиях дальнейшей интеграции цифровых технологий.

Ключевые слова: политика, политическая система, цифровое общество, большие данные, политические практики

\section{Введение}

Сегодня двумя наиболее обсуждаемыми событиями, происшедшими на мировой политической арене за последние годы, среди прочих, безусловно, являются победа на президентских выборах в США в 2016 г. Дональда Трампа и Брексит. Эти события подвергались и подвергаются анализу со многих сторон, но в наши дни на передний план вышел один важный ракурс, который верно подметил британский журналист Джордж Монбио: именно эти события стали первыми громкими заявками о наличии в политической системе готовых к эффективному практическому применению новых цифровых технологий, а конкретно - о применении психометрической аналитики больших данных [Monbiot 2017].

Аутсорсинговая фирма Cambridge Analytica, которую, как сообщается, привлек избирательный штаб Дональда Трампа, консультировала по поводу стратегии проведения кампаний, массированно отслеживая действия людей в социальных сетях. Предлагаемая ею технология психометрически профилирует людей, используя общедоступные данные, и отслеживает их действия в социальных медиа $W e b 2.0$. Далее они использовали эти данные для создания персонализированных цифровых рекламных кампаний, где воздействие на сознание миллионов потенциальных избирателей производилось на личностном уровне.

Успех применения этой модели и ряда алгоритмов свидетельствует, что в ближайшее время политическая система, интерпретируемая в т.ч. и как система обмена информацией, межличностных, групповых и общественных коммуникаций а также взаимодействия и взаимовоздействия между человеком/группой/социумом и политическим институтом/отраслью/системой в целом, в ближайшее время будет претерпевать мощнейшее трансформирующее воздействие в рамках процесса дальнейшего вхождения в цифровое общество и интеграции новейших информационно-аналитических средств, инструментов и технологий в повседневную политическую реальность.

\section{Традиционная парадигма как основание проигрыша Хиллари Клинтон}

В течение самого длительного времени абсолютное большинство политтехнологов и консультантов во всем мире сегментировали предвыборную аудиторию 
посредством сочетания как демографических, так и географических характеристик. Тщательный анализ этой технологии уже давно показывал ее неэффективность в связи с изрядной степенью «уравниловки». Выход из этого положения пытались искать, применяя стандартную информационную стратегию, предполагавшую привлечение как можно более широкой аудитории. Идея подразумевает, что все женщины должны получать одно и то же сообщение по принципу пола или что все пожилые (старые) или молодые люди получают одно и то же сообщение просто вследствие демографических особенностей. Такой подход предполагает постоянное информационное воздействие на аудиторию в целом, что в основном связано с отсутствием персонализации (учета четких характеристик целевой аудитории).

Именно по такой модели работал предвыборный штаб Хиллари Клинтон, которая воспользовалась теми кадрами, которые работали еще на выборах ее мужа в 1992 гг. и позже - в его администрации (Джон Подеста, Джейк Салливан, Юма Абердин и пр.). Штаб был выстроен очень сложно и объединял профессиональных референтов и ассистентов, работающих в этой сфере 25-30 лет. Они, как выяснилось, недооценили Трампа и его штаб, считая его «легкой добычей», будучи догматично уверены, что электорат Обамы автоматически переходит к Клинтон, чего не произошло.

Штаб Хиллари Клинтон воспользовался традиционными, но уже устаревшими схемами организации информационного взаимодействия с массами избирателей, в основе которых была стратификация и группировка, причем выделенные 16 групп априори признавались гомогенными (модель Уорнера). Так, в этих рамках в штабе стало господствовать представление о том, что базовый электорат Клинтон можно охарактеризовать как «Уитни Хьюстон без наркотиков и с ученой степенью». Это молодые 25-40-летние женщины, афроамериканки, мексиканки и белые, феминистки, имеющие высокое образование и ориентированные на карьеру. Для них Клинтон - живое воплощение возможности добиться успеха и самореализоваться в карьере, поэтому для них формировался так называемый универсальный информационный посыл, реализуемый через традиционные СМИ. Считалось, что он будет верно принят большинством электората и вызовет необходимую реакцию. Этого в ожидаемом объеме не произошло. Стремясь компенсировать недостатки стратегии, штаб Клинтон наращивал информационное воздействие, в результате чего Хиллари «приелась» избирателям, да и сама вела себя как своего рода «кандидат-киборг», не допуская человеческой реакции на вызовы.

\section{Политическое психографирование как тренд}

Итак, психография! Она представляет собой изучение личности, ценностей, мнений, взглядов, интересов и образа жизни ${ }^{1}$. Все это объединяется в человеческую внутреннюю сущность, которая напрямую влияет на наш процесс принятия решений. Именно личность управляет поведением, а поведение, в свою очередь, определяет, как мы голосуем. Согласно этой парадигме, именно сочетание одинаковых «психологических» данных и применение аналитики Big Data и помогло Дональду Трампу победить на президентских выборах 2016 г. Сегодня господствует предположение, что компания Cambridge Analytica как на выборах в США, так и на референдуме в ЕС помогла получить данные из Facebook, Twitter, WhatsApp, Telegram и использовать их для определения личностных про-

1 Brookbank A. 2017. Why Psychographic Data Must Be Used in Marketing Campaigns. - Coupsmart. March 28. 
филей конкретных людей, а затем адаптировать политическую рекламу к их психосоциальным характеристикам.

Благодаря тому, что сотни тысяч и миллионы американцев, а позже -англичан попали в исследовательскую орбиту Cambridge Analytica, эта компания смогла сформировать модель для квалифицирования личности каждого взрослого гражданина в США и Великобритании [Hunter 2017]. Зная индивидуальность людей, на которых ориентировались агитаторы предвыборного штаба, они смогли персонализировать конкретные политические кампании, чтобы более эффективно контактировать с этими ключевыми группами аудитории. Таким образом, Cambridge Analytica разработала стратегический алгоритм для автоматизации возможности отслеживать и анализировать содержательное присутствие кандидатов в социальных сетях. Благодаря этому они оптимизировали рекламу для миллионов потенциальных избирателей, используя машинное обучение, чтобы показать им адаптированные новости, которые соответствуют их политической идентичности.

Это, как показала практика, устранило необходимость догадок о том, какое обращение, идейное и формализованное, сможет или не сможет сработать. Они также смогли использовать сотни и тысячи отдельных точечных данных о целевых аудиториях, чтобы до начала процесса общения точно понять, какие сообщения подойдут для какой аудитории. Это и вызывает тревогу: так мы можем манипулировать или управлять даже самими собой, вовсе и не осознавая этого. Онлайн-информация поддается манипуляциям и политическим злоупотреблениям уже с того момента, как эра больших данных едва началась. В сочетании с достижениями в области когнитивной лингвистики и нейробиологии эти технологии могут стать мощным инструментом для изменения предпочтений и решений, которые мы принимаем.

\section{Большие данные и изменение политической среды}

Политическое использование больших данных, по существу, протекает сегодня в ракурсе той же стратегии, что и их коммерческое использование, начавшееся немного ранее. Работа с ними предполагает создание профилей для миллионов людей на основе анализа и обобщения их активности в Интернете. На основе этих профилей аналитики ИТ-компаний, нанятые политическими партиями, могут разрабатывать стратегии, позволяющие наилучшим образом манипулировать мнением конкретных людей, основываясь на их индивидуальности, с целью изменения или сохранения политических предпочтений в обществе [Alexander 2017]. Именно этим и занималась компания Cambridge Analytica для штаба Д. Трампа, приобретая личные данные из различных источников, таких как земельные реестры, регистрационные данные автовладельцев, данные о покупках, членстве в клубах, наличии медицинских скидочных карт и пр.

Эти данные были актуализированы и объединены с избирательными списками Республиканской партии и иными онлайн-данными для расчета личностных профилей. Помимо опоры на большие данные, агитаторы Трампа проверили более 175000 различных вариантов $A D$ для своих аргументов по ходу агитации. Для оптимального психологического целеполагания к объектам пропаганды были применены такие новшества, как различные заголовки, цвета и подписи как в онлайн-рекламе, так и на документах. С июля 2016 г. участникам кампании Трампа было предоставлено онлайн-приложение, из которого они могли определить политические взгляды и типы личности жителей конкретного дома, вплоть до квартиры. Идентичную модель позже реализовывали и участники кампании по Brexit [Grassegger, Krogerus 2017].

Агитаторы Трампа обращались только к тем домохозяйствам, которые при- 
ложение оценило как восприимчивые к его посылу. Далее в дело вступали инструкции для общения, адаптированные к типу личности жителя. По итогам разговора агитаторы отправляли информацию о реакциях на обращение в приложение, где она обобщалась, а новые данные аналитики возвращались на информационные панели штаба Трампа. Подход включал разделение населения США на 32 типа личности, дифференцированных по 17 типам отдельных штатов, где были выработаны 544 профиля, что свидетельствует о беспрецедентно персонализированном подходе, который, в конечном итоге, привел к победе Трампа на выборах.

Обобщая проведенное рассмотрение, следует отметить, что, если указанные тренды сохранятся, мы находимся в начальной фазе изменения политической реальности. Его главным фактором сегодня выступает то, что технологии в очередной раз серьезно опередили в своем развитии существующую политическую культуру и наиболее распространенные в обществе политические практики. Здесь особенно остро встает вопрос о демократии: огромный потенциал больших данных, аналитики и онлайн-форумов будет использоваться для ее укрепления или разрушения. По этому поводу Дж. Монбио утверждает, что общество должно обратить особое внимание на использование этих технологий, т.к. регулятивные институты современной политической системы не имеют надлежащей структуры для защиты масс от манипулирования и злоупотребления технологиями, которые используются людьми, стремящимися к получению власти любым путем. С одной стороны, это может привести к новому политическому нигилизму, который способен окончательно разуверить широкие массы в демократии и дестабилизировать политическую среду на цивилизационном уровне [Monbiot 2018], а с другой - будут появляться все более и более отточенные инструменты манипулирования как сознанием целевой аудитории, так и массовым сознанием в целом.

Первые залпы этого процесса гремят по всему миру уже сегодня. Одними из первых с ними столкнулась американская политическая система, когда перед ней встал вопрос о так называемых фейковых новостях (англ. - fake news). В наши дни, да и последнее время в целом, особенно с развитием сетей Интернет, все громче и громче звучат сетования, а иногда и прямые обвинения тех или иных социально-политических акторов в создании ложных информационных сообщений - фейковых новостей. В январе 2018 г. этот вопрос, например в США, стал предметом для разбирательства на заседании американского сената. Сенатор Джефф Флэйк, озаглавивший свое выступление «Правда и демократия», отмечал, что 2017 г. стал переломным в истории национальной политической системы. По его словам, именно тогда администрация Дональда Трампа при его согласии и содействии ввела в общественный оборот и закрепила в нем такое явление, как «альтернативные факты», в качестве оправдания тому, что раньше называлось просто ложью ${ }^{1}$. В свою очередь, сам президент Трамп в ряде выступлений высказал претензии к свободной прессе (ее свобода гарантирована Конституцией США), назвав ее «врагом народа» (the enemy of the people).

Все это продиктовано теми возможностями по манипулированию массовым сознанием, которые достигаются при использовании технологий создания и распространения ложных новостей, которые сегодня все более и более повышают уровень правдоподобности информации, тогда как технология распространения уже давно отработана на так называемых вирусных моделях продвижения в Интернете. Она основана на массированных перепостах того или

\footnotetext{
${ }^{1}$ Prepared remarks for Sen. Jeff Flake, who delivered a speech to the Senate on Jan. 17, 2018. URL: https:// www.politico.com/story/2018/01/17/full-text-jeff-flake-on-trump-speech-transcript-343246 (accessed 14.02.2018).
} 
иного изображения, видео или текста на других сайтах и в социальных сетях. Здесь активно вступает в дело технология $w w w$-ботов, т.е. компьютерных программ, имитирующих действия людей в Интернете, которые поддерживают и промоутируют необходимую стейкхолдерам новость (информацию), раскручивая ее до тех пор, пока не будет достигнут искомый результат или не станет понятно, что для его достижения она (фейк-новость) непригодна.

Источник таких манипуляций, если рассматривать более широко, кроется в когнитивно предвзятом отношении, изменениях в информационной системе (включая рост социальных сетей и круглосуточный цикл поступления новостей), не совпадающих (конкурирующих) требованиях различных социальных групп и страт к информационной системе, которые ограничивают ее способность идти в ногу с изменениями в общественной системе. Последствия этого процесса проявляются во многих отношениях. Самыми разрушительными из них в отношении перспектив демократии могут быть названы такие, как эрозия гражданского дискурса, отчуждение и самоотстранение широких масс граждан от политических и гражданских институтов, неопределенность социума в отношении политики государства и пр., вплоть до деструкции политической системы.

В свете возможности такого развития событий в Российской Федерации уже формируется система противодействия, главным узлом которой стал федеральный закон «О внесении изменений в Кодекс Российской Федерации об административных правонарушениях», предусматривающий блокировку недостоверных и искажающих факты (фейковых) новостей ${ }^{1}$. Вопрос, однако, вызывает возможная практика использования этого инструмента, способного превратиться в новый механизм цензуры.

Данная статья написана в рамках выполнения государственного задания по теме НИР на 2019-2021 г2. «Российское общество перед новыми вызовами: динамика социально-экономического положения, ценностных ориентаций и социального участия различных групп населения».

\section{Список литературы}

Alexander S. 2017. Democracy at risk: the terrifying power of «big data». - Online Opinion: E-journal. March 23. P. 13-15.

Grassegger H., Krogerus M. 2017. The Data That Turned the World Upside Down. - Motherboard. Jan 28. URL: https://motherboard.vice.com/en_us/article/how-ourlikes-helped-trump-win (accessed 04.05.2019).

Hunter F. 2017. «Psychographic» data firm behind shock Trump victory considers Australian expansion. - Sidney Morning Herald. 23 Jan.

Monbiot G. 2017. Big data's power is terrifying. That could be good news for democracy. - The Guardian. 06 March.

Monbiot G. 2018. The Mind Hackers. - The Guardian. 31 Dec.

\footnotetext{
1 Федеральный закон от 18.03.2019 № 27-Ф3 «О внесении изменений в Кодекс Российской Федерации об административных правонарушениях». Доступ: http://www.consultant.ru/document/ cons_doc_LAW_320399/(проверено 04.05.2019).
} 